\title{
Review
}

\section{Immunodiagnosis of Tuberculosis: State of the Art}

\author{
Lancelot M. Pinto ${ }^{a, b} \quad$ Jasmine Grenier ${ }^{a, b}$ Samuel G. Schumacher ${ }^{c}$ \\ Claudia M. Denkinger ${ }^{d}$ Karen R. Steingart ${ }^{e}$ Madhukar Pai ${ }^{a, b}$ \\ ${ }^{a}$ Department of Epidemiology, Biostatistics and Occupational Health, McGill University, and \\ ${ }^{\mathrm{b}}$ Respiratory Epidemiology and Clinical Research Unit, Montreal Chest Institute, Montreal, Qué., Canada; \\ 'London School of Hygiene and Tropical Medicine, London, UK; ${ }^{d}$ Beth Israel Deaconess Medical Center,

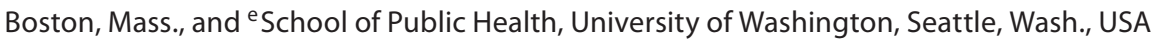

\section{Key Words}

Tuberculosis • Diagnosis $\cdot$ Immunodiagnostics $\cdot$ Serological tests $\cdot$ Interferon $-\gamma$ release

\begin{abstract}
Undiagnosed and mismanaged tuberculosis (TB) continues to fuel the global TB epidemic. Rapid, accurate and early diagnosis of TB is therefore a priority to improve TB case detection and interrupt transmission. Although considerable improvements have been made in TB diagnostics, there are two major gaps in the existing diagnostics pipeline: (1) lack of a simple accurate point-of-care test that can be used for rapid diagnosis at the primary care level; (2) lack of a biomarker (or combination of biomarkers) that can be used to identify latently infected individuals who will benefit most from preventive therapy. Currently available commercial serological (antibody detection) tests are inaccurate and do not improve patient outcomes. Despite this evidence, dozens of serological tests are sold and used in countries (e.g. India) with weak regulatory systems, especially in the private sector. Recognizing the threat posed by these suboptimal tests, a World Health Organization (WHO) Expert Group has strongly recommended against the use of serological tests for the diagnosis of pulmonary and extra-pulmonary TB. Another WHO Expert Group has discouraged the use of inter-
\end{abstract}

feron- $\gamma$ release assays for active pulmonary TB diagnosis in low- and middle-income countries. All existing tests for latent TB infection appear to have only modest predictive value and further research is needed to identify highly predictive biomarkers.

Copyright $\odot 2011$ S. Karger AG, Base

\section{Introduction}

Although the global expansion of DOTS, the Stop TB Strategy, has been successful and has saved millions of lives, tuberculosis (TB) incidence is not falling as rapidly as expected in many countries [1] in part because of the HIV epidemic and also because of the emergence of multi-drug resistant (MDR) and extensively drug-resistant TB. The most recent Global TB Control report (2010) showed that 9.4 million new TB cases were reported in 2009, and 1.7 million people died from TB [2]. Undiagnosed $\mathrm{TB}$, delayed diagnosis, and mismanaged TB continue to fuel the global TB epidemic [3]. Rapid, accurate and early diagnosis of TB is therefore a top priority to improve global TB case detection, which is currently only $63 \%$ for all forms of TB [2].

Traditionally, the diagnosis of active pulmonary TB disease has relied on 1 of 3 approaches: direct visualiza-

\section{KARGER}

Fax +41613061234

E-Mail karger@karger.ch

www.karger.com
(C) 2011 S. Karger AG, Basel

$1011-7571 / 12 / 0211-0004 \$ 38.00 / 0$

Accessible online at:

www.karger.com/mpp
Dr. Madhukar Pai, MD, PhD

McGill University, Department of Epidemiology and Biostatistics 1020 Pine Ave. West

Montreal, QC H3A 1A2 (Canada)

Tel. +1 514398 5422, E-Mail madhukar.pai@mcgill.ca 
Fig. 1. Overview of types of immunodiagnostics for TB, current evidence, and major recommendations for use. IGRAs = In vitro interferon- $\gamma$ release assays.

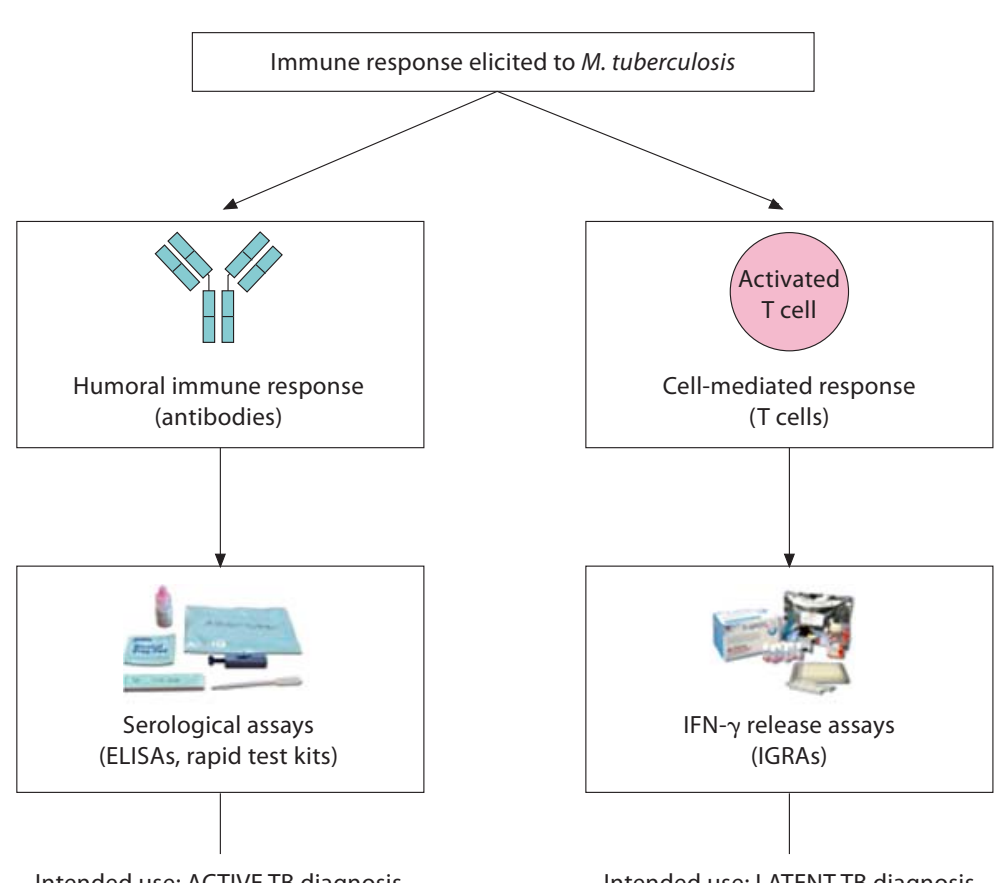

Intended use: ACTIVE TB diagnosis

Intended use: LATENT TB diagnosis

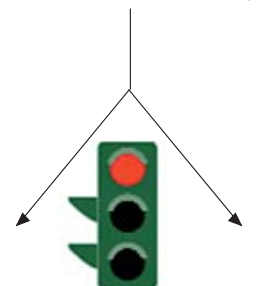

\begin{tabular}{l||l}
\cline { 2 - 2 } $\begin{array}{l}\text { Current evidence: } \\
\text { - Serological tests } \\
\text { are inaccurate } \\
\text { and produce } \\
\text { highly } \\
\text { inconsistent } \\
\text { results }\end{array}$ & $\begin{array}{l}\text { Recommendations: } \\
\text { - WHO has issued a } \\
\text { negative policy } \\
\text { advising against } \\
\text { the use of } \\
\text { serological tests } \\
\text { for detection of } \\
\text { active TB }\end{array}$ \\
$\begin{array}{l}\text { None of the } \\
\text { serologing } \\
\text { can replace } \\
\text { sputum } \\
\text { microscopy }\end{array}$ & \\
\end{tabular}

urrent evidence:

- IGRAs are highly specific tests for latent TB

- They cannot distinguish between latent TB and active disease

recommended against their use for active TB disease tion of Mycobacterium tuberculosis (MTB) using microscopy, growth and isolation of MTB (using culture) and amplification and detection of MTB nucleic acids (nucleic acid amplification tests, NAAT). While microscopy, culture and NAATs are commonly used, each has its strengths and limitations. For latent TB infection (LTBI), the diagnostic options have always been immune-based, given that none of the three options (i.e. smears, culture, NAAT) for active TB work for LTBI. Broadly, immunodiagnostics for TB can be grouped into two categories (fig. 1): serological (antibody detection) assays based on humoral immune response; and tests of cellular immune 
Table 1. Published evidence on serological tests for TB

\begin{tabular}{llll}
\hline $\begin{array}{l}\text { Form of } \\
\text { tuberculosis }\end{array}$ & $\begin{array}{l}\text { Type and number of } \\
\text { studies/tests evaluated }\end{array}$ & Major findings & Reference (source) \\
\hline Pulmonary & commercial (68) & $\begin{array}{l}\text { sensitivities (10-90\%) and specificities } \\
(47-100 \%) \text { were inconsistent }\end{array}$ & Steingart et al. [5] (systematic review) \\
\hline Extrapulmonary & commercial (21) & $\begin{array}{l}\text { sensitivities (0-100\%) and specificities } \\
(59-100 \%) \text { were inconsistent }\end{array}$ & Steingart et al. [6] (systematic review) \\
\hline Pulmonary & $\begin{array}{l}\text { rapid commercial tests } \\
(19)\end{array}$ & $\begin{array}{l}\text { sensitivities (1-60\%) and specificities } \\
(53-99 \%) \text { were inconsistent }\end{array}$ & $\begin{array}{l}\text { WHO/TDR [7] laboratory-based evaluation } \\
\text { of 19 commercially available rapid diagnostic } \\
\text { tests for tuberculosis; 2008 (report) }\end{array}$ \\
\hline
\end{tabular}

response (tuberculin skin test, TST, and in-vitro interferon- $\gamma[$ IFN- $\gamma]$ release assays [IGRAs]). While serological assays are intended for active TB diagnosis, TST and IGRAs are intended for LTBI detection.

\section{Serological (Antibody) Assays for Active TB Diagnosis}

Serological assays have been in use for many years, although no international guideline has recommended their use. In fact, the International Standards for TB Care discourage the use of these tests [4]. These assays are commercially available in two formats: ELISA-based laboratory assays; and rapid immunochromatographic tests intended to be used as point-of-care (POC) tests. A large number of studies have evaluated the performance of serological tests, and these have been summarized in systematic reviews $[5,6]$. In addition, UNICEF/UNDP/ World Bank/World Health Organization (WHO) Special Programme for Research and Training in Tropical Diseases recently published an evaluation of 19 commercially available rapid serological tests for TB [7].

Available evidence, summarized in table 1, clearly shows that serological tests for TB are inaccurate (with highly inconsistent estimates of sensitivity and specificity) and that there is no evidence that these tests improve patient outcomes. In fact, because of false-negative and false-positive results, patients can be misdiagnosed, causing harm, diagnostic delays, morbidity and mortality [8]. Despite this evidence, dozens of different serological tests are sold and used in countries with weak regulatory systems, including countries such as India, China, Brazil, South Africa, Pakistan, Bangladesh and Indonesia. Recent reports in the media have highlighted the case of
India, where an estimated 1.5 million $\mathrm{TB}$ serological (ELISA) tests are done every year (mostly in the private sector) at an expenditure conservatively estimated at USD 15 million per year $[8,9]$. Media reports have also emphasized the fact that serological kits are not approved for use in the high-income countries (e.g. France, UK, USA, Canada, Australia, Japan), where they have been developed, and instead are exported to low- and middleincome countries with weak regulatory systems [9]. For example, anda-TB (Anda Biologicals, Strasbourg, France) and Pathozyme TB (Omega Diagnostics Ltd, Alva, Scotland, UK) are the most commonly used serological tests in Indian private laboratories, and they are exported from companies in France and Scotland, UK, respectively, where these tests are not clinically used.

Recognizing the potential harm posed by these suboptimal tests, the WHO convened an Expert Group in July 2010 to review the evidence on TB serological tests. Based on published evidence and expert opinion, the WHO Expert Group concluded that commercial serological tests provide inconsistent and imprecise estimates of sensitivity and specificity. There is no evidence that existing commercial serological assays improve patient-important outcomes. Overall data quality was graded as very low and the Expert Group strongly recommended against the use of these tests for the diagnosis of pulmonary and extra-pulmonary TB [10]. On 27 September 2010, this recommendation was approved by STAG-TB, the highest policy making body for TB at WHO [10]. A negative WHO policy on TB serology was published in July 2011 [10], as highlighted by a recent Lancet World Report which provided an insightful analysis of the situation [9]. The WHO policy does not discourage research in serological tests. In fact, the WHO strongly encourages research because immunological 
discovery research may eventually produce tests that may be helpful as POC rapid tests that are currently missing in the TB diagnostics pipeline [9].

\section{IGRAs for Latent TB Diagnosis}

The development of IGRAs has been a recent advance in the diagnosis of LTBI. IGRAs are in vitro blood tests of cell-mediated immune response; they measure $\mathrm{T}$ cell release of IFN- $\gamma$ following stimulation by antigens that are unique to $\mathrm{MTB}$, including early secreted antigenic target 6 (ESAT-6) and culture filtrate protein 10 (CFP10). These antigens are more specific for TB than purified protein derivative because they are not shared with any BCG vaccine strains or certain species of nontuberculous mycobacteria (e.g. M. avium) [11]. Two IGRAs are available in many countries: the QuantiFERON-TB ${ }^{\odot}$ Gold In-Tube (QFT-GIT) assay (Cellestis Ltd., Vic., Australia) and the T-SPOT.TB $^{\odot}$ assay (Oxford Immunotec, Abingdon, UK). Both tests are approved by the US Food and Drug Administration, and are also available in Europe and many other countries.

A large number of studies have evaluated IGRAs and based on several systematic reviews and recently updated guidelines [12-28], the following summary points can be made about their accuracy, performance and operational characteristics (summarized in table 2):

IGRAs, like the TST, are surrogate markers of MTB infection. They indicate a cellular immune response to recent or remote sensitization with MTB. Therefore, in their current format, IGRAs cannot distinguish between latent infection and active TB disease [27]. Similar to the TST, a positive IGRA result may not necessarily indicate active TB and similarly, a negative IGRA result may not rule out active disease in persons with suspected TB $[25$, 27]. Specificity of IGRAs is poor in patients with suspected active TB in high TB burden settings, and this suggests that IGRAs may not be useful as a rule-in test for active $\mathrm{TB}$ in $\mathrm{TB}$ endemic countries with a high background prevalence of LTBI $[25,27]$. Overall, IGRAs and TST are not intended for active TB diagnosis in adults $[25,27,29]$. Indeed, a recent WHO recommendation reinforces this message [10].

IGRAs have excellent specificity (>95\%) for latent TB infection that is not affected by BCG vaccination $[13,25]$. Specificity in this context refers to estimates from lowrisk individuals with no known $\mathrm{TB}$ exposure in low $\mathrm{TB}$ incidence countries. In contrast, the specificity of TST varies across populations depending on timing of BCG and whether repeated (booster) vaccinations are given [30]. For example, some countries recommend booster BCG vaccinations post-infancy and into adolescence and this can compromise the value of TST. IGRAs may be more helpful for LTBI diagnosis in such countries. A World Atlas of BCG Policies and Practices (www.bcgatlas.org) has been recently compiled to help clinicians and public health practitioners better interpret TST and decide on populations where the more specific IGRAs may be more appropriate than the TST [31]. Another webbased resource (www.tstin3d.com) has been developed to facilitate the interpretation of TST as well as IGRAs.

Using culture-confirmed active TB as a surrogate reference standard for latent $\mathrm{TB}$ infection, the sensitivity for T-SPOT.TB appears to be higher than QFT-GIT or TST (approximately 90, 80, and 80\%, respectively) [25, 27]. The higher sensitivity of T-SPOT.TB may be useful for evaluating individuals with immunosuppressive conditions.

IGRA sensitivity appears to be lower in culture-proven active TB patients in high incidence settings (as compared to sensitivity in low incidence settings) $[25,27]$. Thus, a negative IGRA result should not be used to rule out active TB disease [27].

Just as HIV infection compromises TST performance, HIV infection appears to compromise IGRA sensitivity, and lower CD4 counts are associated with higher rates of indeterminate IGRA results; this is especially the case with QFT-GIT [24, 27]. TSPOT appeared to be relatively less affected by immunosuppression than QFT-GIT and tuberculin skin testing, likely because the testing platform ensures that an adequate number of peripheral blood mononuclear cells are available despite overall low CD4+ cell counts in whole blood [24].

Both IGRA and TST results correlate well with risk factors and surrogate markers of TB exposure [28], but the magnitude of the association varies across populations. In most low TB incidence countries, TST results are associated with BCG, while IGRA results are not (and this often results in TST+/IGRA- type of discordant results).

IGRA-positive contacts have a higher incidence of active TB than IGRA-negative contacts, but the association is modest. The majority of those who are IGRA-positive do not seem to progress to active TB disease (this is also true for TST) [32, 33]. In fact, the totality of evidence suggests that all existing LTBI tests (TST and IGRAs) appear to have only modest predictive value and may not help identify those who are at highest risk of progression to TB disease. Based on the evidence thus far, IGRAs appear to have similar predictive value as the TST [32]. 
Table 2. A comparison of TST versus IGRAs

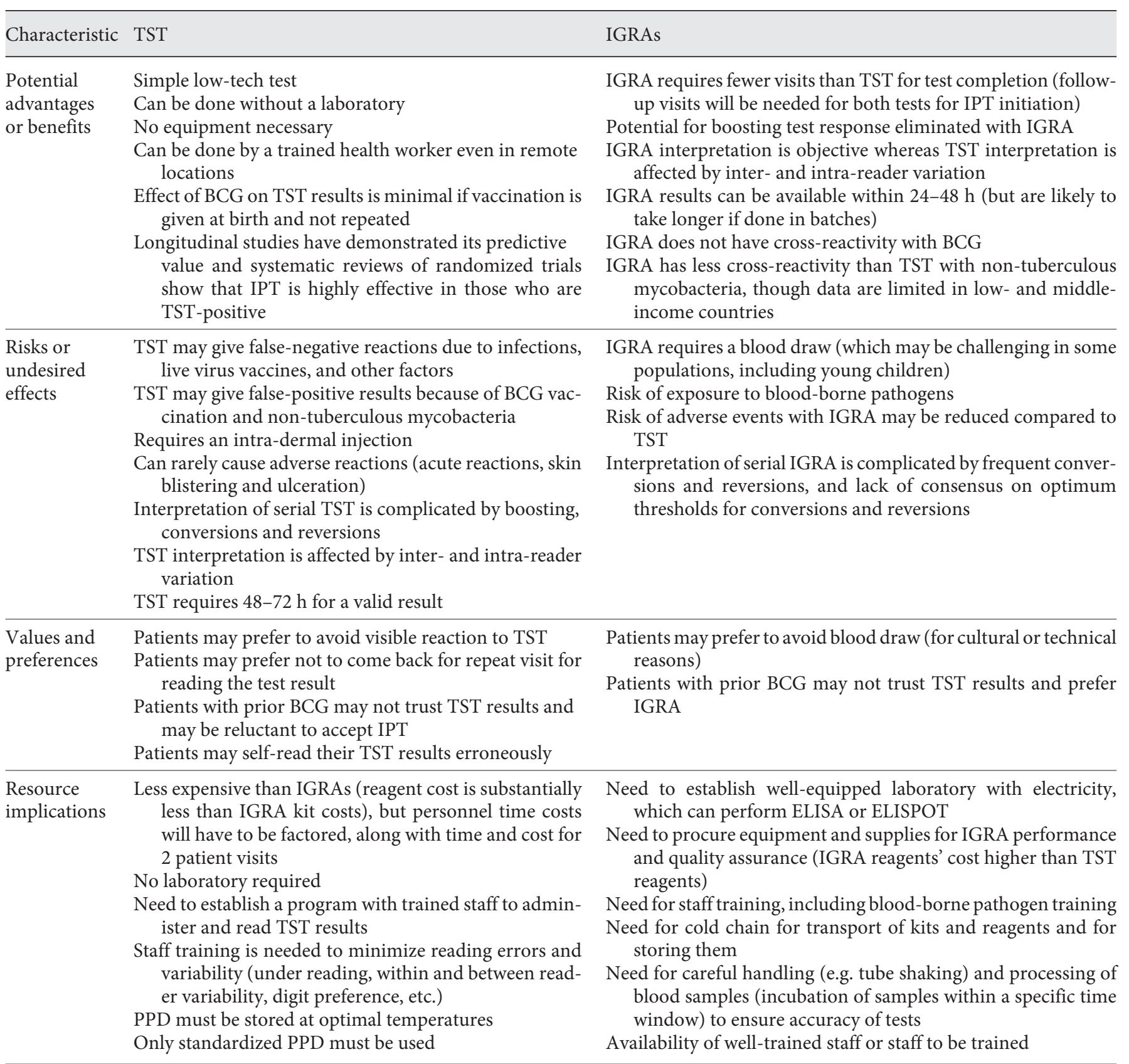

$\mathrm{BCG}=$ Bacillus Calmette-Guérin vaccine; IPT = isoniazid preventive therapy; $\mathrm{PPD}=$ purified protein derivative.

Even among contacts in high TB incidence settings, the majority of those with positive IGRA results do not seem to progress to TB disease, suggesting that IFN- $\gamma$ alone may not be sufficient as a prognostic biomarker [32, 33], especially in high TB burden settings where repeated infections are highly likely. It may be necessary to mea- sure additional biomarkers, or incorporate biomarkers with other known risk factors into a composite risk prediction model.

IGRAs are dynamic tests and conversions and reversions are frequently observed during serial testing $[23$, 34]. The interpretation of such dynamic IFN- $\gamma$ kinetics is 
unclear. The optimum criteria for defining IGRA conversions and reversions are yet to be determined [34].

Available evidence does not support the use of IGRAs for monitoring therapy of active disease or latent TB infection. Monitoring of active TB therapy must continue to rely on sputum smears and culture.

There is some evidence that IGRAs done on specimens from the site of the disease (e.g. broncho-alveolar lavage fluids) may add some diagnostic value in smear-negative TB [25], but this requires further evaluation. Furthermore, site-specific specimens are not easy to obtain in resource-limited settings.

From an operational perspective, the reagent (kit) costs of IGRAs are substantially higher than costs of TST, and unlike the TST, IGRAs require laboratories with trained staff that can perform ELISA or ELISPOT assays. IGRAs require blood draws and this may be challenging in young children. Errors in collecting, labeling, or transporting blood specimens, or while performing and interpreting these assays, can affect their accuracy. Also, IGRAs require fresh blood samples and transportation delays can affect test performance.

IGRA requires fewer visits than TST for test completion (although follow-up visits will be needed for both tests for initiation of therapy for LTBI) and results can potentially be available in $24-48 \mathrm{~h}$. The risk of adverse events with IGRA may be reduced compared to TST. Unlike the TST, IGRAs can be repeated without the risk of sensitization and boosting. IGRA interpretation is objective, whereas TST interpretation is affected by inter- and intrareader variation. A major challenge for implementing TST is failure of test individuals to return for the reading.

While IGRAs are reliable and fairly robust in field conditions, there are operational issues such as time to incubation, power outages, and tube shaking that must be adequately addressed. Test kits must be transported and stored in optimum conditions to prevent exposure to excessive heat. Strict quality assurance is necessary to detect unusual patterns in results (e.g. spike in numbers of indeterminate results due to low mitogen response). It is critically important to run both positive and negative controls with each assay, and adequate attention must be paid to training of laboratory technicians.

\section{Major Guidelines on IGRAs}

The use of IGRAs is increasing in low or intermediate TB incidence countries. More than twenty countries (almost all low TB incidence settings) now have at least one guideline or statement on the use of IGRAs $[35,36]$. The only guideline to explicitly address use of IGRAs in lowand middle-income countries with high TB incidence is the recommendation by the WHO [10].

In these guidelines, three main approaches have been recommended for the use of IGRAs: (1) TST should be replaced by IGRAs; (2) either TST or IGRAs may be used; (3) two-step approach of TST first, followed by IGRA. As seen in table 3 , there is considerable diversity in how various countries currently recommend and use IGRAs [35, 36]. The two-step approach of TST followed by IGRA seems to be the most dominant strategy and this may partly be due to cost considerations. Some European countries (e.g. Germany, Denmark, Switzerland) have strongly favored the use of IGRAs in individuals on immunosuppressive medications such as TNF- $\alpha$ blockers.

\section{Gaps in the TB Diagnostics Pipeline and Future Prospects for Improved Tests}

In recent years, considerable improvements have been made in TB diagnostics (and information has been summarized and made easily accessible through a new website www.tbevidence.org, by the Stop TB Partnership) and the current pipeline (fig. 2) is a significant improvement over the situation in the past $[19,33]$. However, there are two major gaps in the existing diagnostics pipeline: lack of a simple accurate POC test for TB that can be used for rapid diagnosis at the primary care level; lack of a biomarker (or combination of biomarkers) that can be used to accurately identify latently infected individuals who will benefit most from preventive therapy. The Stop TB Partnership's New Diagnostics Working Group anticipates that a POC test for active TB may become available by 2013 , and a LTBI predictive biomarker test may become available by 2015 , and these goals (fig. 2) are now incorporated into the revised Global Plan to Stop TB (2011-2015) [37].

At present, the only assay that comes close to being a POC test is the $\mathrm{Xpert}^{\odot} \mathrm{MTB} / \mathrm{RIF}$ assay (Cepheid Inc, Sunnyvale, Calif., USA) for rapid molecular diagnosis of TB [38]. On December 8th, 2010, the WHO announced its endorsement/approval of this cartridge-based automated NAAT test, which can accurately detect TB and rifampin resistance in less than $2 \mathrm{~h}$ with minimal handson technical time [39]. Preliminary studies of this system suggest diagnostic performance comparable to culture, the current gold standard [38]. The Xpert MTB/RIF assay is a fully integrated and automated system that is 
Table 3. Summary of major guidelines on IGRAs

\begin{tabular}{|c|c|c|}
\hline $\begin{array}{l}\text { Country/ } \\
\text { region }\end{array}$ & Source of guideline & Major recommendations on IGRAs \\
\hline USA & $\begin{array}{l}\text { United States Center for } \\
\text { Disease Control (CDC), } \\
2010[16]\end{array}$ & $\begin{array}{l}\text { IGRAs can be used in place of (but not in addition to) TST in all situations in which CDC } \\
\text { recommends TST as an aid in diagnosing MTB infection with preferences and special con- } \\
\text { siderations. This includes contact investigations, testing during pregnancy, and screening of } \\
\text { health care workers and others undergoing serial evaluation for MTB infection. Despite the } \\
\text { indication of a preference, use of the alternative test (FDA-approved IGRA or TST) is accept- } \\
\text { able in medical and public health practice. Populations in which IGRAs are preferred for test- } \\
\text { ing: } \\
\text { - Persons who have received BCG (either as a vaccine or for cancer therapy); and } \\
\text { - Persons from groups that historically have poor rates of return for TST reading. } \\
\text { TST is preferred over IGRAs for testing children less than } 5 \text { years of age. }\end{array}$ \\
\hline
\end{tabular}

Canada Canadian Tuberculosis

IGRAs are not recommended for the diagnosis of active TB in adults.

Committee, 2010 [17]

Evidence of TB infection in children is often used in making a diagnosis of active TB, in addition to symptoms, radiological abnormalities, history of exposure, and microbiological investigations such as microscopy and culture. While collection of clinical specimens for definitive microbiologic diagnosis remains paramount, IGRAs may be used as a supplementary diagnostic aid in combination with the TST and other investigations to help support a diagnosis of TB. A negative IGRA (or TST) does NOT rule out active TB at any age and especially not in young children.

IGRAs may be used as a confirmatory test for a positive TST in contacts (adult or child) who, on the basis of an assessment of the duration and degree of contact with an active infectious case, are felt to have a low pretest probability of recently acquired LTBI and who have no other high risk factors for progression to active disease if infected.

For close contacts or those contacts who have high or increased risk of progression to active disease if infected, a TST (or both TST and IGRA) should be used, and if either is positive the contact should be considered to have LTBI.

In an immunocompromised person (adult or child), the TST should be the initial test used to detect LTBI. If the TST is positive, the person should be considered to have LTBI. However, in light of the known problem with false-negative TST results in immunocompromised populations, a clinician still concerned about the possibility of LTBI in an immuno-compromised person with a negative initial TST result may perform an IGRA test.

\begin{tabular}{ll}
\hline UK & UK National Institute \\
& for Health and Clinical \\
& Excellence (NICE),
\end{tabular}

To diagnose latent TB in:

Excellence (NICE), $2011[50]$

Household contacts aged 5 years and older and non-household contacts of all people with active TB:

- A Mantoux test should be performed. Those with positive results (or in whom Mantoux testing may be less reliable - for example, people who have had the BCG vaccination) should then be considered for interferon-gamma release assay (IGT).

- If Mantoux testing is inconclusive, refer the person to a TB specialist.

New entrants from high-incidence countries aged 5-15 years:

- Offer a Mantoux test followed by IGT if positive.

New entrants from high-incidence countries aged 16-34 years:

- Offer either IGT alone or a dual strategy. For people aged 35 years or older, consider the individual risks and benefits of likely subsequent treatment before offering testing.

New entrants from high-incidence countries aged under 5 years:

- Use Mantoux as the initial test. If positive, taking into account BCG history, refer to a TB specialist to exclude active disease and consider treatment of latent TB.

People who are immunocompromised:

- If latent TB is suspected in children and young people who are immunocompromised, refer to a TB specialist.

- For people with HIV and CD4 counts of less than 200 cells $/ \mathrm{mm}^{3}$, perform an IGT and a concurrent Mantoux test. If either test is positive assess for active TB and consider treating for latent TB.

- For people with HIV and CD4 counts of 200-500 cells/ $\mathrm{mm}^{3}$, perform an IGT alone or an IGT with concurrent Mantoux test. If either test is positive, assess for active TB and consider treating for latent TB.

Low and middle World Health Orga-

IGRAs should not be used as a replacement for conventional microbiological diagnosis of income countries nization, $2010[10]$ pulmonary and extra-pulmonary TB in low- and middle-income countries 

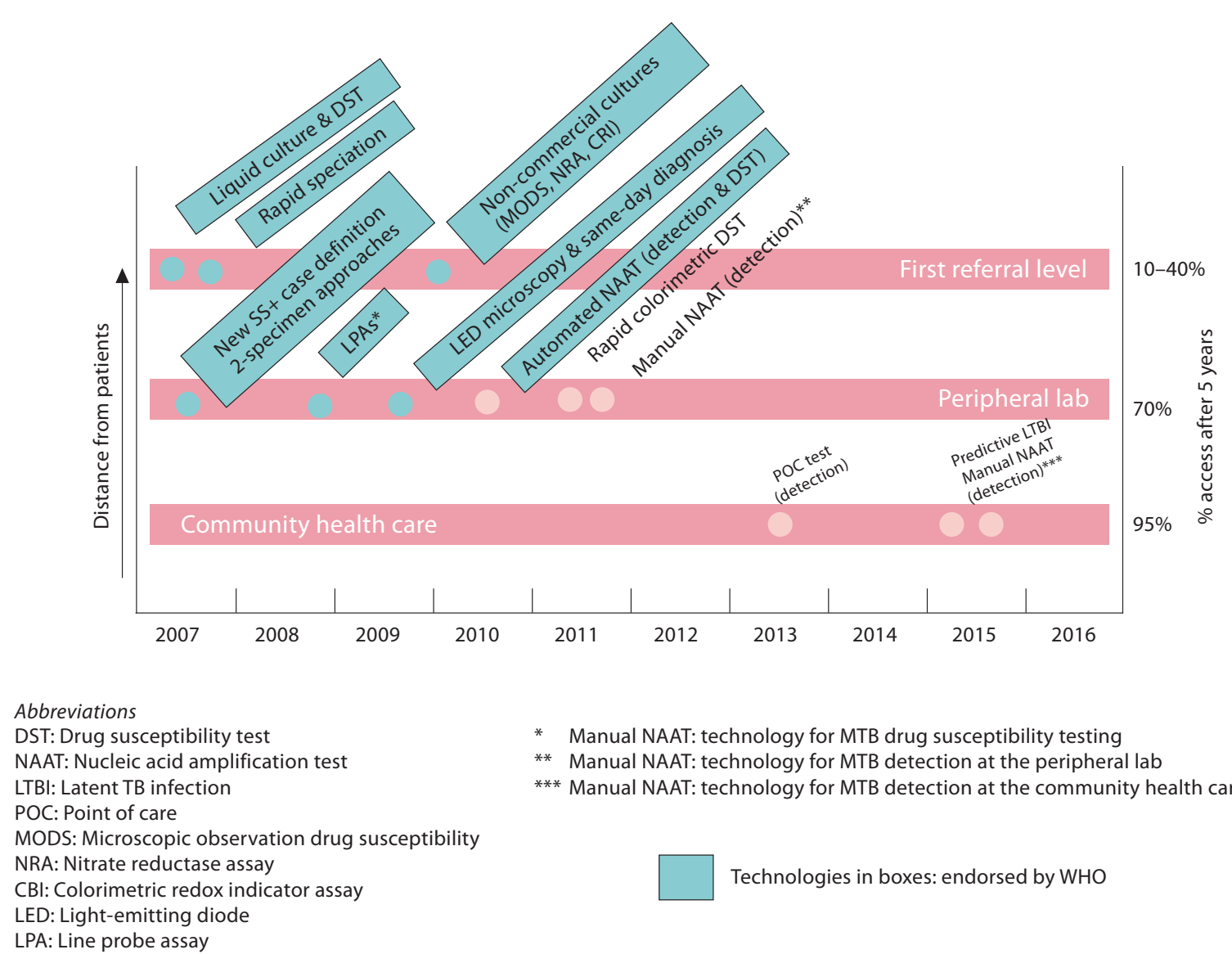

Fig. 2. Current TB diagnostics pipeline. Source: Stop TB Partnership's New Diagnostics Working Group, adapted from WHO [37].

simple to perform with minimal training, is not prone to cross-contamination, requires minimal biosafety facilities, and has a high sensitivity in smear-negative TB. Thus, the assay can be placed closer to the patients, in a clinic setting without the need for laboratory infrastructure [40]. The GeneXpert platform can be used for a variety of disease conditions, including health-care associated infections such as Clostridium difficile and methicillin-resistant Staphylococcus aureus.

In the policy roadmap released in December 2010 [39], the WHO Expert Group recommended that: Xpert MTB/ RIF should be used as the initial diagnostic test in individuals suspected of MDR-TB or HIV-associated TB (strong recommendation); Xpert MTB/RIF may be used as a follow-on test to microscopy in settings where MDR and/or HIV is of lesser concern, especially in smear-negative specimens (conditional recommendation, recogniz- ing major resource implications). These recommendations have been backed by volume-based price reductions to make the test more affordable [39]. Efforts are currently underway to scale up this technology, although cost still remains a major barrier for scale-up [40]. In addition to high cost, other potential limitations include the need for continuous electricity, stable temperature, storage facilities and equipment maintenance.

Substantial investments are being made in meeting the Global Plan goals for diagnostics, including biomarker research [33], novel antigen discovery [41], use of combination of antigens to improve performance [42], and exploitation of technologies such as high-throughput detection of antibodies to the entire MTB proteome [43] and transcriptional biomarkers with potential as diagnostic tools [44]. Also, newer studies on the Xpert MTB/ RIF technology suggest great promise [45-48], and could 
potentially have a big impact if they can be used to replace ineffective serological tests in high-burden countries [49].

Thanks to these efforts, the next few years should see exciting advances that will complete the TB diagnostics pipeline, and help control TB. However, product development will not by itself result in public health impact. The impact of new tests will depend on the manner and extent of their introduction and scale-up, the strength of the laboratories in which they are used, and the degree to which access to appropriate therapy follows access to diagnosis. Translation of scientific progress into real impact is critical, and may be possible with political commitment, increased funding and engagement of all stakeholders.

\section{Acknowledgements}

L.M.P. received fellowship support from McGill University Health Centre's Research Institute, and Shastri Indo-Canadian Institute. M.P. is a recipient of funding from Canadian Institutes of Health Research (CIHR), EDCTP (TBNEAT) and European Commission (TBSusgent, EUFP7). None of the funding agencies had any involvement with this publication.

\section{Disclosure Statement}

There are no financial conflicts. K.R.S. and M.P. are affiliated with the Stop TB Partnership's New Diagnostics Working Group. M.P. is a consultant for the Bill and Melinda Gates Foundation. These organizations had no involvement with this publication.

\section{References}

-1 Lönnroth K, Castro KG, Chakaya JM, Chauhan LS, Floyd K, Glaziou P, Raviglione MC: Tuberculosis control and elimination 20102050: cure, care, and social development. Lancet 2010;375:1814-1829.

2 World Health Organization: Global tuberculosis control 2010. Geneva, World Health Organization, 2010.

-3 Dye C, Williams BG: The population dynamics and control of tuberculosis. Science 2010;328:856-861.

-4 Hopewell PC, Pai M, Maher D, Uplekar M, Raviglione MC: International standards for tuberculosis care. Lancet Infect Dis 2006;6: $710-725$.

5 Steingart KR, Flores LL, Dendukuri N, Schiller I, Laal S, Ramsay A, Hopewell PC, Pai M: Commercial serological tests for the diagnosis of active pulmonary and extrapulmonary tuberculosis: an updated systematic review and meta-analysis. PLoS Medicine 2011;8:e1001062.

-6 Steingart KR, Henry M, Laal S, Hopewell PC, Ramsay A, Menzies D, Cunningham J, Weldingh K, Pai M: A systematic review of commercial serological antibody detection tests for the diagnosis of extra-pulmonary tuberculosis. Thorax 2007;62:911-918.

7 World Health Organization and UNICEF/ UNDP/World Bank/WHO Special Programme for Research and Training in Tropical Diseases: Laboratory-based evaluation of 19 commercially-available rapid diagnostic tests for tuberculosis. Geneva, World Health Organization, 2008.

8 Specter M: A Deadly Misdiagnosis. Is it possible to save the millions of people who die from TB? New Yorker, 15 November 2010.

$\checkmark 9$ Morris K: WHO recommends against inaccurate tuberculosis tests. Lancet 2011;377: 113-114.
10 World Health Organization. Policy Statement: Commercial serodiagnostic tests for diagnosis of tuberculosis. WHO, Geneva, Switzerland, 2011. http://whqlibdoc.who.int/ publications/2011/9789241502054_eng.pdf.

11 Andersen P, Munk ME, Pollock JM, Doherty TM: Specific immune-based diagnosis of tuberculosis. Lancet 2000;356:1099-1104.

12 Menzies D, Pai M, Comstock G: Meta-analysis: new tests for the diagnosis of latent tuberculosis infection: areas of uncertainty and recommendations for research. Ann Intern Med 2007;146:340-354.

13 Pai M, Zwerling A, Menzies D: T-cell based assays for the diagnosis of latent tuberculosis infection: an update. Ann Intern Med 2008; 149:177-184.

14 van Zyl-Smit RN, Zwerling A, Dheda K, Pai $\mathrm{M}$ : Within-subject variability of interferon$\mathrm{G}$ assay results for tuberculosis and boosting effect of tuberculin skin testing: a systematic review. PLoS ONE 2009;4:e8517.

15 Chang KC, Leung CC: Systematic review of interferon-gamma release assays in tuberculosis: focus on likelihood ratios. Thorax 2010;65:271-276.

16 Mazurek M, Jereb J, Vernon A, LoBue P, Goldberg S, Castro K: Updated guidelines for using interferon gamma release assays to detect Mycobacterium tuberculosis infection - United States, 2010. MMWR Recomm Rep 2010;59:1-25.

17 Canadian Tuberculosis Committee: Recommendations on Interferon Gamma Release Assays for the Diagnosis of Latent Tuberculosis Infection - 2010 Update. Can Commun Dis Rep 2010;36:1-21.

18 Smith R, Cattamanchi A, Metcalfe JZ, Steingart K, Hopewell P, Pai M: Systematic review of sensitivity of interferon-gamma release assays for detection of $M$. tuberculosis infection in HIV-infected patients. Am J Respir Crit Care Med 2010;181:A2264.
19 Pai M, Minion J, Steingart K, Ramsay A: New and improved tuberculosis diagnostics: evidence, policy, practice, and impact. Curr Opin Pulm Med 2010;16:271-284.

20 American Academy of Pediatrics: Tuberculosis. Red Book 2009;181. http://aapredbook. aappublications.org.

21 Pai M, Riley LW, Colford JM Jr: Interferongamma assays in the immunodiagnosis of tuberculosis: a systematic review. Lancet Infect Dis 2004;4:761-776.

22 Dheda K, van Zyl Smit R, Badri M, Pai M: Tcell interferon-gamma release assays for the rapid immunodiagnosis of tuberculosis: clinical utility in high-burden versus lowburden settings. Curr Opin Pulm Med 2009; 15:188-200.

23 Zwerling A, van den Hof S, Scholten J, Cobelens F, Menzies D, Pai M: Interferon-gamma release assays for tuberculosis screening of healthcare workers: a systematic review. Thorax 2011, E-pub ahead of print.

24 Cattamanchi A, Smith R, Steingart KR, Metcalfe JZ, Date A, Coleman C, Marston BJ, Huang L, Hopewell PC, Pai M: Interferongamma release assays for the diagnosis of latent tuberculosis infection in HIV-infected individuals - a systematic review and metaanalysis. J Acquir Immune Defic Syndr 2011; 56:230-238.

25 Sester M, Sotgiu G, Lange C, Giehl C, Girardi E, Migliori GB, Bossink A, Dheda K, Diel R, Dominguez J, Lipman M, Nemeth J, Ravn P, Winkler S, Huitric E, Sandgren A, Manissero D: Interferon-\{gamma\} release assays for the diagnosis of active tuberculosis: a systematic review and meta-analysis. Eur Respir J 2011;37:100-111.

26 Pai M, Menzies D: Interferon-gamma release assays for latent tuberculosis infection (version 18.3). Waltham, UpToDate, 2010. 
27 Metcalfe JZ, Everett C, Steingart K, Cattamanchi A, Huang L, Hopewell PC, Pai M: Interferon-gamma release assays for active pulmonary TB diagnosis in adults in lowand middle-income countries: systematic review and meta-analysis. J Infect Dis 2011, in press.

28 Mandalakas AM, Detjen A, Hesseling AC, Benedetti A, Menzies D: Interferon-gamma release assays and childhood tuberculosis: systematic review and meta-analysis. Int J Tuberc Lung Dis 2011;15:1018-1032.

29 Lange C, Pai M, Drobniewski F, Migliori GB: Interferon-gamma release assays for the diagnosis of active tuberculosis: sensible or silly? Eur Respir J 2009;33:1250-1253.

- 30 Farhat M, Greenaway C, Pai M, Menzies D: False-positive tuberculin skin tests: what is the absolute effect of BCG and non-tuberculous mycobacteria? Int J Tuberc Lung Dis 2006;10:1192-1204.

- 31 Zwerling A, Behr M, Varma A, Brewer TF, Menzies D, Pai M: The BCG World Atlas: a database of global BCG vaccination policies and practices. PLoS Medicine 2011;8: e1001012.

32 Rangaka MX, Wilkinson KA, Glynn JR, Ling D, Menzies D, Mwansa-Kambafwile J, Fielding K, Wilkinson RJ, Pai M: Predictive value of interferon- $\gamma$ release assays for incident active tuberculosis: a systematic review and meta-analysis. Lancet Infect Dis 2011, Aug 14, Epub ahead of print.

-33 Wallis RS, Pai M, Menzies D, Doherty TM, Walzl G, Perkins MD, Zumla A: Biomarkers and diagnostics for tuberculosis: progress, needs, and translation into practice. Lancet 2010;375:1920-1937.

-34 Pai M, O’Brien R: Serial testing for tuberculosis: can we make sense of T cell assay conversions and reversions? PLoS Medicine 2007;4:e208.

35 Pai M, Minion J, Sohn H, Zwerling A, Perkins M: Novel and improved technologies for tuberculosis diagnosis: progress and challenges. Clin Chest Med 2009;30:701-716.
6 Denkinger CM, Dheda K, Pai M: Guidelines on interferon- $\gamma$ release assays for tuberculosis infection: concordance, discordance or confusion? Clin Microbiol Infect 2011;17: 806-814.

37 World Health Organization: Global Plan to Stop Tuberculosis 2011-2015. Geneva, World Health Organization, 2010.

38 Boehme CC, Nabeta P, Hillemann D, Nicol MP, Shenai S, Krapp F, Allen J, Tahirli R, Blakemore R, Rustomjee R, Milovic A, Jones M, O’Brien SM, Persing DH, Ruesch-Gerdes S, Gotuzzo E, Rodrigues C, Alland D, Perkins MD: Rapid molecular detection of tuberculosis and rifampin resistance. $\mathrm{N}$ Engl J Med 2010;363:1005-1015.

39 World Health Organization: Roadmap for rolling out Xpert MTB/RIF for rapid diagnosis of TB and MDR-TB 2010. www.who.int/ tb/laboratory/roadmap_xpert_mtb_rif_ rev23dec2010.pdf.

40 Small PM, Pai M: Tuberculosis diagnosis time for a game change. N Engl J Med 2010; 363:1070-1071.

-41 Young DB, Perkins MD, Duncan K, Barry CE 3rd: Confronting the scientific obstacles to global control of tuberculosis. J Clin Invest 2008;118:1255-1265.

42 Steingart KR, Dendukuri N, Henry M, Schiller I, Nahid P, Hopewell PC, Ramsay A, Pai M, Laal S: Performance of purified antigens for serodiagnosis of pulmonary tuberculosis: a meta-analysis. Clin Vaccine Immunol 2009; 16:260-276.

43 Kunnath-Velayudhan S, Salamon H, Wang HY, Davidow AL, Molina DM, Huynh VT, Cirillo DM, Michel G, Talbot EA, Perkins MD, Felgner PL, Liang X, Gennaro ML: Dynamic antibody responses to the Mycobacterium tuberculosis proteome. Proc Natl Acad Sci USA 2010;107:14703-14708.

44 Berry MP, Graham CM, McNab FW, Xu Z, Bloch SA, Oni T, Wilkinson KA, Banchereau R, Skinner J, Wilkinson RJ, Quinn C, Blankenship D, Dhawan R, Cush JJ, Mejias A, Ramilo O, Kon OM, Pascual V, Banchereau J, Chaussabel D, O'Garra A: An interferon-inducible neutrophil-driven blood transcriptional signature in human tuberculosis. Nature 2010;466:973-977.
45 Boehme CC, Nicol MP, Nabeta P, Michael JS, Gotuzzo E, Tahirli R, Gler MT, Blakemore R, Worodria W, Gray C, Huang L, Caceres T, Mehdiyev R, Raymond L, Whitelaw A, Sagadevan K, Alexander H, Albert H, Cobelens F, Cox H, Alland D, Perkins MD: Feasibility, diagnostic accuracy, and effectiveness of decentralised use of the Xpert MTB/RIF test for diagnosis of tuberculosis and multidrug resistance: a multicentre implementation study. Lancet 2011;377:1495-1505.

46 Nicol MP, Workman L, Isaacs W, Munro J, Black F, Eley B, Boehme CC, Zemanay W, Zar HJ. Accuracy of the Xpert MTB/RIF test for the diagnosis of pulmonary tuberculosis in children admitted to hospital in Cape Town, South Africa: a descriptive study. Lancet Infect Dis 2011, Jul 15, Epub ahead of print.

-47 Lawn SD, Brooks SV, Kranzer K, Nicol MP, Whitelaw A, Vogt M, Bekker LG, Wood R: Screening for HIV-Associated tuberculosis and rifampicin resistance before antiretroviral therapy using the Xpert MTB/RIF assay: a prospective study. PLoS Medicine 2011;8:e1001067.

48 Scott LE, McCarthy K, Gous N, Nduna M, Van Rie A, Sanne I, Venter WF, Duse A, Stevens W: Comparison of Xpert MTB/RIF with other nucleic acid technologies for diagnosing pulmonary tuberculosis in a high HIV prevalence setting: a prospective study. PLoS Medicine 2011;8:e1001061.

-49 Dowdy DW, Steingart KR, Pai M: Serological testing versus other strategies for diagnosis of active tuberculosis in India: a cost-effectiveness analysis. PLoS Medicine 2011;8: e1001074

50 National Institute for Health and Clinical Excellence: Clinical guideline 117. Tuberculosis: clinical diagnosis and management of tuberculosis, and measures for its prevention and control. London, NICE, 2011. www.nice. org.uk/nicemedia/live/13422/53642/53642. pdf. 